\title{
MATI HINT JA LÕUNAEESTI LUMM
}

Mati Hindi suhet lõunaeesti keelega iseloomustab ehk kõige paremini tema enda lause raamatu „Keel on tõde on õige ja vale" (2002) annotatsioonist: „Olen sündinud lõunaeestlasena ja suudan tartukeelsesse (halvemini võrukeelsesse) jutuajamisse lülituda praktiliselt kohe." Hindist nooremad eesti kultuuriinimesed sageli ainult arvavad, et nad saavad selles keeles hakkama. Hint teab, et lõunaeesti, nii tartu kui võru variandis, on keel - autonoomne süsteem, mille mõistmine või mittemõistmine on intuitiivselt tajutav peaaegu igaühele, kes seda keelt lapsest saadik on piisavalt palju kuulnud ja kõnelnud. Hint teab, aga ei kiitle sellega. Kiitlemine, bravuur on üldse midagi sellist, mis tundub Mati Hindi loomuses täielikult puuduvat ja mida ta ka kaaskõnelejate väidetes armutult maha kiskuda tavatseb. Eks sellepärast võivad tema suhted mõnede bravuursete võrukeste ja setudega teinekord pingelisedki olla. Aga Hint on siiski oma, tõsine ja vastutustundlik oma, kes soovib südamest lõunaeesti keele kõige paremat käekäiku.

Mati Hint on kogunud ja kirjutanud taustu avava raamatu „Minu vaade maale ja merele: raamat Madise mälestuseks" (2007). Suguvõsa lugu, perekondade ja kohtade lugu selles hakkas kokku kõlama Marju Lauristini raamatus „Punane ja sinine” (2010) LõunaEesti esivanematest kirjutatuga. Taustal veel Traat, Kõiv ja teisedki, aga rohkem kunstipärases žanris. LõunaTartumaa suured talud, suguvõsa talud on mälestustes igaüks omaette mikrokosmos. Igast talust kujuneb ka nappides kirjeldustes ainulaadne kombinatsioon loodusest, oue ja hoonete dominantidest, põlvnemisloost ja pererahvast, inimestest, kes on selle koha osaks saanud. Kui neid inimesi enam pole, kaotab ka koht võlu, sinna nagu ei tahakski enam olnud elu jälgedesse tuhnima minna. Hindi puhul meeldib mulle, kuidas tal on jätkunud tunnustust nendele tema jaoks võhivõõrastele inimestele, kes on suguvõsa talud oma käe järgi korda teinud, kellel on omanikutunnet.

Tundes tänaseid Lääne-Võrumaa vanu inimesi, tean ma, kui väga oluline on see koht, kus elatakse. Iga päev on täis mõtteid ja muret selle pärast, kuidas kodu korras hoida, kust noorperemees võib kaevata veetrassi või teha uue tee, et see olemasolevaid puid ja põõsaid kõige vähem kahjustaks, kustkaudu võib aeda sisse sõita puukoormaga traktor, kui kaua püsivad püsti vanad ouepuud, mis ähvardavad maja peale kukkuda, aga mille mahavõtmiseks käsi ei tõuse. Põlvkond, kelle muretult alanud lapsepõlve hakkas toona varjutama arutu ja ülbe vägivald nii inimese kui ka elukeskkonna kallal, ei talu vanaks saanuna lagastamist vähimalgi määral. Ju nii ongi õige.

Mati Hindi vahekord lõunaeesti keelega on kujundlikult võttes samalaadne. Tema töö on alati olnud seotud eesti keelega, aga tartu keel on keelelise isakoduna ikka alles, sinna saab minna ja sinna Mati Hint minu kujutluses lähebki, sest keegi teine ei „nõsta sääl kõrt kõrre pääle".

Järgnevalt toon välja tähelepanekud, mida väärtuslikku on Mati Hint siiani lõunaeesti keeles esile tõstnud, et see on ka võrukesele meelde jäänud ja nende mõttekäikude aluseks saanud.

\section{Välted ja verbimuutmine}

Mati Hint (2000) on publitseerinud oma mamma (selles põlvkonnas tähendab see sõna peaaegu alati 'vanaema') Aliide Reidolfi suulisi meenutusi, märkides kolmandat väldet järjekindlamalt ja palatalisatsiooni vähem kui 
näiteks tekstikogu „Tartumaa saja-aastaste jutud" (1995). Iseenesest võimalikult lihtsat ja eestipärast kirjaviisi pooldav Hint on siin kõneldud keele omapära esile toonud just väldete täpse märkimise kaudu ja suutnud edasi anda ehk mõneti üllatavagi tõsiasja, et Rõngu ja Lääne-Võrumaa keelepruugid on väldete osas täiesti identsed. Välted on tähtsad ja see, et nad tähtsad on, et keelekasutajad suudavad mängeldes minimaalpaare välja pakkuda, loob eeldused ajalooliselt redutseerunud morfoloogilise süsteemi püstipüsimiseks. Võrukesed on oma kirjaviisi kujundades väldete märkimisest loobunud, aga eks loobumine ole ajendatud kartusest, et kõik see, mida morfoloogiliseks eristuseks (näiteks keele õpetamisel) vaja on, tungib kohe ka tarbekirjaviisi. Nüüd pakutakse võimalust eristada olevikku ja minevikku $s$-lõpulises 3. pöördes palatalisatsiooniga: (olevik) pilkas (minevik) pilgaś, arvas - arvaś, vinnas - vinnaś. Pole üldse kindel, kas see palatalisatsioon seal ka kõigis võru keele variantides olemas on, aga välteopositsioon on alati olemas ja Hindi (poolfoneetiline) kirjaviis toob esile selle, mis on ühine nii Võru-, Setu- kui ka Lõuna-Tartumaale: pil kass - pilgass, vinnass - vinnass, a'rvass - arvass (Hint 2002: 183). Neid minimaalpaare eristab eelkõige III ja II välte vaheldus. Kui öelda, et paneme eristajaks palatalisatsiooni, siis on asi kirjutamisõpetuse jaoks hädapäraselt aetud, teisevälteliselt hääldatud sõnas jääb hääldusenergiat üle küll, et sõnalõpu $s$-ile pisut palatalisatsiooni lisada.

Hindi üheks oluliseks teeneks tartu keele verbimorfoloogia teadvustamisel on mõnes kirjutises (nt Hint 2008: 553) riivamisi mainitud, aga sagedamini vestlustes välja tulnud seisukoht, et tartu kirjakeele oleviku 3. isiku $p$-lõpp (eeltoodud näidete järgi pilkap, arvap, vinnap) polnud Rõngu rahva jaoks küll mingi rahvakeel. Samast asjast on mul- le rääkinud Mats Traat Otepää lääneosast Arulast, et tartu kirjakeele ütlep on täitsa võõras. Nii on selgelt teada, et vähemalt lõunapoolsemas tartu keeles muutuvad verbid samamoodi kui võru keeles. Vähe sellest, isegi Mulgimaal Karksis leidis Karl Pajusalu aastakümneid tagasi üles kõik lõunaeesti vanad verbimuutetüübid. Muidugi olid need Pajusalu mulkidest keelejuhtidel segamini uuemate, põhjaeestipäraste vormidega (Pajusalu 1996).

\section{Palatalisatsioon}

Hint on lõunaeesti verbimorfoloogias kõige huvitavamaks nähtuseks pidanud ajakategooria eristamist palatalisatsiooni või selle puudumisega. Sellest on ta pidanud ka ettekande rahvusvahelisel uralistika sümpoosionil 1989. aastal. Oleviku and ja mineviku and, oleviku võtt ja mineviku võt't on küll keeleajalooliselt lihtsasti seletatavad $i$-minevikust $i$ kadumisega, aga et ka kadunud asjad võivad ikka olemas olla ja ennast teisel kujul meelde tuletada, sellised fenomenid on omased just kohakesksele Lõuna-Eestile.

Hint on ühte meelt teiste lõunaeesti uurijatega: lõunaeestlased suudavad palataliseerida kõiki konsonante ja eristada kõigi konsonantide palataliseeritust. „Kas pole juba seegi fantastiline, et lõunaeestlaste ajudes on oma etalonid (mälupesad) paljude palataliseeritud konsonantide äratundmiseks, mida kirjakeelsetel põhjaeestlastel pole? Meie identsus, meie kordumatus asub eelkõige meie ajus ning keelelise identsuse erinevusega kaasneb ka üldise identsuse erinevus" (Hint 2002: 181). Lõunaeesti palatalisatsioon on teist tüüpi kui põhjaeesti keeles ja täidab edukalt morfofonoloogilise markeri rolli. Pisut kahtlev on Hint olnud Hella Keema seisukoha suhtes, et võru ja tartu keelt eristab palatalisatsiooni tüüp. Tema oma kodukeel Keema kirjel- 
datud Tartu murde epenteetilist palatalisatsiooni ei tunne. Epenteetilise palatalisatsiooniga liitub harilikult see markantne keelejoon, et säilinud $i$-le eelnev konsonant hääldub selgelt palataliseerimatult, tumedalt, võiks öelda lausa „hiidlaslikult” nt $O^{i} t t$ : Oti. Ka see nähtus pole Rõngu murrakus tajutav. On olemas krestomaatiline kaart raamatust "Tartu murde tekstid" (Keem 1970: 43), mis näitab, et võrupärane palatalisatsioon oli üle vana Tartumaa piiri levinud vaid piiratud ulatuses. Hindile ja ka oma välitöökogemusele toetudes julgen küll vastu väita, et kogu tartu keele lõunaosa ja läänevõru keelepruugi palatalisatsioon on pigem sama tüüpi. Muidugi võib leida sõnavara tasandil erandeid, nt lõunatartlaste laits, mis läänevõrukestel on ikka latś. Epenteetiline palatalisatsioon on täiesti kindlalt olemas Lõuna-Tartumaa põhjaosa murrakutes, sealhulgas ka Võnnus.

\section{Võru oma kirjaviisi eelduste puudumine}

Võru ja tartu keeleliste ühisjoonte, ühise algupära rõhutamise kõrval on Hindi jaoks alati olnud tähtis võru keele kui lõunaeesti kirjakeele pärija kujunemine - suunad, eesmärgid, liialdused, nõrkused. Hint on rõhutanud võrukeste vastutust lõunaeesti keele edasikandmisel. Loomulikult puutub asi kohe kirjaviisi. Erinevalt mõnest võru liikumise ideoloogist pole Hint siiski kurjalt nõudnud, et võõrtähtedega kirjutamine tuleb ära lõpetada. „Ortograafiline leidlikkus on võru liikumise oma asi, aga liigsuur traditsioonist kaugenemine ei saa tulla võru keele taasünnile kasuks, nii nagu ka liiga terav vastandumine ülejäänud Eestile ei aita levitada võru kultuuri tähtsuse mõistmist" (Hint 2002: 195). Igal juhul pooldab Hint ise praeguses olukorras täielikult eesti keele kirjaviisiga koos- kõlas olevat ortograafiat, kus ka $q$-st larüngaalklusiili märgina tuleks loobuda. Lugejaid, kes loeksid valdavalt võru keeles ja eelistatult alati võru keeles, lihtsalt pole ja neid pole ka kusagilt tulemas. „Kas polnud ka vana saksapärane kirjaviis eesti keelele küllalt hea niikaua, kui seda lugesid sagedamini need, kes elasid saksakeelset elu? Kas on ainult ajalooline juhus, et uus kirjaviis lahkus saksapäraselt aluselt sel ajal, kui kirjaoskus muutus üldiseks ja eestikeelset kirjavara hakkas kiiresti juurde tekkima? Ortograafiline iseseisvus muutus võimalikuks, kui tekkis lugejaskond, kes realiseeris oma lugemis- ja kirjutamisoskust eesti keeles" (2002: 197). Hint võib möönda, et eesti kirjaviis sobib võru keelele vaevaliselt, kuid ta ei usu, et tänapäeva võrukesed sellest vähegi erinevat kirjaviisi eelistada võiksid.

Võru ortograafia tänapäevaseisus on Mati Hint kritiseerinud sõnalõpu pika $s$-i kirjutamist ühekordselt. Tundub ju arutu teha raskesti reeglistatav ja ainult kirjapildi ilule rõhuv otsus kirjutada tetäs, makas, kasvi suurõs, isegi hä̈̈ miis ja pada kiis, samal ajal kui on ka lühikese $s$-iga häälduvaid sõnu nagu (uhkeldaja kohta) tuus, luminõ kuus, või Hargla teistest erinevas häälduses hä̈̈ miis. Hurda kirjaviisi $z$ ja $s$-i paar (kuuz tuudi tarrõ terves kuus) on ka unustusse jäänud ja sellest polegi kahju. Setu noorte hulgas tuleb küll ette "Setukeste laulude” lugemist-laulmist helilise $z$-ga. Teisalt hääldavad ajakirjanikud tartukeelseid perekonnanimesid juba valdavalt „zumistades” [zirk], [za`hkna], [zi`lmer], [zopp], kuigi $z$ tähistab neis afrikaati. Kuna nimede õigekirja pole õnnestunud normida (p.o Tsirk, Tsahkna, Tsilmer, Tsopp), siis oleks tore, kui Mati Hint selle koha pealt sõna võtaks, et vähemalt ringhäälingu toimetajad saaksid traditsiooniliste nimede õige häälduse meelde jätta. 


\section{Mõõdukuse nõue}

Ortograafiast on niikuinii saanud võru keele arendamise umbsõlm. Oma sõnavara loomine ja juurutamine võiks olla see positiivseks peetav suund, millega eesti inimest, eestistunud või kohe eestistuvat lõunaeestlast võru keelest huvituma panna. On selge, et iseseisvas, kultuurilist lisaväärtust pakkuvas võru keeles ei taha keegi näha võru uusmurret - ümberpandud eesti kantseliiti võru morfoloogia ja foneetikaga. Nagu teisedki, näeb Hint siin vajakajäämist: „Kui võrrelda liitsõnu soome, eesti ja võru keeles, siis on üldpilt see, et soome ja eesti liitsõnad ning tuletised on iseseisvad, aga võru liitsõnad ja tuletised on sageli eesti keelest üle võetud ning kohandatud võru hääldusega" (2002: 198). Samal ajal teab Hint hästi, kui tähtis on säilitada mõõdutunne keele sõnavaralises ja väljenduslikus uuendamises: „Küsimus on, kui palju iseseisvaid liitsõnalisi või iseseisva tuletusstruktuuriga termineid kannab võru keel välja? Kas võtaks keskklass järsult rikastatud ja omapärastatud keele vastu või oleks see jõukohane üksnes eliidile?" (2002: 199).

Kümmekond aastat hiljem on läinudki nii, et värav taaselustatud ja uuendatud võru sõnade kirjas läbilaskmiseks on tegelikult kitsas. Eesti-võru sõnaraamatu varsti valmiv, toimetajate ringis juba kasutatav käsikiri ilmutab loomingulisust ja pakub julgelt võrukeelseid sõnu ja väljendeid. Kuid tegevtoimetajad ja tõlkijad (Uma Leht, veebiportaal Lastekas, tõlkelised lasteraamatud, tarbetekstide tõlked) lasevad sõnaraamatu materjali läbi filtri, küsides kogu aeg, kas lihtne lugeja või kuulaja sellest ka aru saab. Praegu ongi see ainuõige tee, et võõristus kirjutatud võru keele suhtes ei kasvaks. Kuid ajapikku võib ületoimetamine esile kutsuda võru kirjakeele lupjumise, seepärast oleks väga vaja, et võru keeles ilmuks rohkem erinevaid, autori isikupärases sõnastuses proosatekste.

\section{Tartu keele lugu}

Vana kirjakeele uurijad on enesestmõistetavalt ametis tartu keele vanimate tekstidega. Mati Hinti on alati rohkem huvitanud tartu keele kirjalikust käibest väljatõrjumise lugu. Kokkuvõtlikult on tema sellesuunaline programm esitatud artiklis „Tartu keele avaliku kasutamise taandareng vajab täpset dokumenteerimist" (Hint 2008). Siin kutsub ta üles algatama doktoritööde tasemel uurimust, kuidas lõunaeestlased oma igapäevast kirjakeelt vahetasid. Hint ei rahuldu üldsõnalise eelduste loetlemisega, vaid peab vajalikuks kaardistada, millistes kirikutes mis ajani jutlustas tartukeelne pastor, kust olid pärit koolmeistrid ja milliseid õpikuid mingis koolis kasutati XIX ja $\mathrm{XX}$ sajandi vahetusel.

Hindi tähelepanekud annavad aimu huvitavast ja hüplikust ajaskaalast. Vallakohtute protokollid on tartu ja tallinna segakeelsed juba 1870 . aastate lõpul. Sõltub muidugi kirjutajast, aga tekstidest on näha, et teist keelt on peenemaks peetud. Minu 1839. aastal sündinud Võrumaa vanavanavanaisal oli elupäevade lõpul sajandivahetuse paiku küllalt väljendusrikas ja hea tartukeelne kirjaoskus. Tema 1870. aastal sündinud poeg kirjutas isale kirju tallinna keeles, aga oli ka koolmeistriks õppinud. Mati Hindi 1880. aastal sündinud vanaema kirjutas omi kirju tartu keeles, ikka külakooli hariduse põhjal, kus tema ajal pidanuks valitsema venekeelne õpetus. Et koolides talitati erinevalt, seda näitab minu kodukandi Sõmerpalu vallakoolide lugu. 1900. aasta paiku õpetas ühes koolitares põhjaeestlasest Jakob Paap (kellest rahvas muide väga lugu pidas), väiksemas Prassi koolitares aga seminariharidusega Urvaste mees Peeter 
Tootsen (snd 1857), kes tegi vähemalt kogu kooli pidamisega seotud kirjatöö vene ja tartu keeles. Tootsenis kutsus tartu keele väljatõrjumine esile trotsi. Kui ta 1920. aastate alguses pärast vaheaega veel sedasama kooli juhatas, püüdis ta jätkuvalt ametlikke aruandeid lõunaeesti keeles täita (Ojala 2012: 90). Võib-olla pole üldse juhus, et samal ajal käis Prassi koolis Rihhard Iher (snd 1910), kellest sai ainus läbinisti võrukeelne luuletaja 1960.-1970. aastate Eestis. Nagu selgub Terje Lõbu magistritöö kokkuvõttest, olid veel Eesti Vabariigi algusaastate koolinõunikud rahulolematud õpetajatega, kes ei teinud katsetki lastega tunnis eesti kirjakeelt kõnelda. Ka õpetajad ise võtsid revidentide ees sõna õiguse eest vähemalt esimese ja teise klassi lastega võru keelt kasutada (Lõbu 2007: 67).
Tartu kirjakeele kõrvaletõrjumise lugu tulebki võtta kui paratamatust, on Hint kokkuvõtvalt leidnud. Kui oleks läinud teisiti, oleks vaat et halvemgi. „Oletuslikus ajaloos Eestimaa kubermangust tekkinud omaette riik oleks olnud ilma Lõuna-Eestita elujõuetum, vähem koolitatud ja nõrgema rahvustundega," hindab Hint lõunaeestlaste panust (2008: 554). Nagu üks õige talupoeg kunagi, ei kannata Mati Hint ülekohut, lõunaeestlaste osa unustamist eesti rahvuse sünni juures. Kui ikka tallu on tuldud uhke kaasavaraga, siis on tulijal õigus mäletada ja tulija hõimul õigus arvustada. Nii on need asjad ajast aega käinud.

EVAR SAAR

\section{Kirjandus}

H int, Mati 2000. Saja aasta eest. Saa aasta iist. Lõuna suguvõsamütoloogia ilu ja hiilgus. - Inter Dialectos Nominaque. Pühendusteos Mari Mustale 11. novembril 2000. Koostanud ja toimetanud Jüri Viikberg. Tallinn: Eesti Keele Sihtasutus, lk 39-52.

$\mathrm{H}$ i n t, Mati 2002. Keel on tõde on õige ja vale. (Eesti mõttelugu 46.) Tartu: Ilmamaa.

Hint, Mati 2008. Tartu keele avaliku kasutamise taandareng vajab täpset dokumenteerimist. - Keel ja Kirjandus, nr 7, lk 553-556.

K e e m, Hella 1970. Tartu murde tekstid. Eesti murded III. Tallinn: Valgus.
Lõ b u, Terje 2007. Määne oll' koolituspoliitiga Võromaal edimädse Eesti Vabariigi aol? - Tartu Ülikooli LõunaEesti keele- ja kultuuriuuringute keskuse aastaraamat VI. Tartu, lk 66-71. O j a l a, Uuno 2012. Sõmmõrpalu mõisaja vallakoolide ajalugu XVIII sajandi keskpaigast kuni Eesti riigi sünnini 1918. - Sõmmõrpalu vallakoolid. Osula kool. Koostaja Heljo Saar. Võru, lk 7-172.

P a j u s a l u, Karl 1996. Multiple Linguistic Contacts in South Estonian: Variation of Verb Inflection in Karksi. (Turun yliopiston suomalaisen ja yleisen kielitieteen laitoksen julkaisuja 54.) Turku. 